\section{Panning for gold in a hot flowing stream}

\author{
Gjergji Shore and Michael G. Organ* \\ www.goldbulletin.org
}

\section{Background}

Over the last decade, gold catalysis has undergone a renaissance leading to new and useful applications in synthetic organic chemistry (1). Unlike its neighbouring d10 metals whose catalysis is typified by changes in oxidation state (generally between 0 and II), gold resists such formal changes due to the high stability of the I and III oxidation states. This aided the belief for some time that gold was catalytically inactive. Indeed, for the first half of the last century gold chemistry was dominated by simple oxidative processes, such as chlorination (2) and oxidation using molecular oxygen (3). This evolved into more elaborate processes including the incorporation of $\mathrm{CO}$, (4) in some cases concurrent with carbon-carbon bond formation (5). The first recognized carbon-carbon bond forming reaction that was catalytic in gold was an asymmetric aldol condensation in 1986 (6).

$\mathrm{Au}(\mathrm{I})$ and $\mathrm{Au}(\mathrm{III})$ complexes, generally as the halide salt, dominate homogeneous catalysis although complexes involving organic ligands are being used increasingly. However, while soluble gold catalysis is sharply on the rise, the gold literature is still dominated by heterogeneous catalysis (1). It is interesting that a number of the transformations catalyzed by gold seem to work, to varying degrees, regardless of the oxidation state of the gold catalyst involved (7). Further, it is puzzling that some processes appear to work equally well when using either soluble gold salts (e.g., $A u(I)$ or $A u(I I I))$ or $A u$ particles, presumably as $\mathrm{Au}(0)(8,9,10)$. That said, it is very challenging with metal particles to rule out the existence of, and therefore the involvement of metal oxides in promoting chemical transformations. The suitability of a range of gold species to catalyze the same reactions has not been explained conclusively. Most likely, one of two situations is at work here: either gold can cycle between different oxidation states
Department of Chemistry, York University, 4700 Keele Street, Toronto, ON, Canada M3J 1 P3

\footnotetext{
*Corresponding author: E-mail: organ@yorku.ca
} 
more readily than portrayed or different mechanisms are operating with different gold species.

The use of gold thin films to promote chemical transformations was pioneered, inadvertently, by deMeijere in 1976 (11). His group had built a goldlined flow reactor with the idea that it would provide an inert surface with which to perform gas-phase thermolysis reactions. In fact, the film was found to be catalytically active in the rearrangement of strained, small-ring compounds. In a similar application, we have been systematically evaluating the performance of metal-film-lined capillaries with flowed reaction solutions $(12,13,14)$. However, in this case the capillaries were irradiated with microwaves to help promote the transformation, presumably in the form of heat. Gold is highly microwave active and will absorb so strongly and generate such heat that the metal will actually sublime (15). None-theless, if the microwave power is controlled, these hot gold films are capable of promoting a wide variety of catalytically-diverse and useful synthetic processes. This report details our use of thin-gold films in microwave-assisted, continuous flow organic synthesis (MACOS).

\section{Synthesis and characterization of thin gold films inside capillaries}

Given the high temperatures that are possible when a thin-metal film is irradiated with microwaves, coupled together with the fact that the reactant stream is constantly flowing against the film's surface, a robust $\mathrm{Au}$ film must be laid down in the reactor. From the perspective of promoting the reaction, it is important to try to maximize surface area of the gold film. This was shown to be true when we prepared a densely-packed, rather flat and featureless film that came from the deposition of gold particles from a diethylene glycol/AuCl ${ }_{3}$ solution. While the film demonstrated good wear-and-tear properties, the catalytic performance in reactions (vide infra) was poor. Conversely, when a highly-porous film surface was prepared from the deposition of goldnanoparticle clusters from an aqueous sodium citrate solution, the film demonstrated poor adhesion to the glass surface and portions of the film were carried out in the effluent of the reactor. The ideal blend of adhesive properties and high surface area were attained when a two-step process was developed. First, the densely-packed gold film

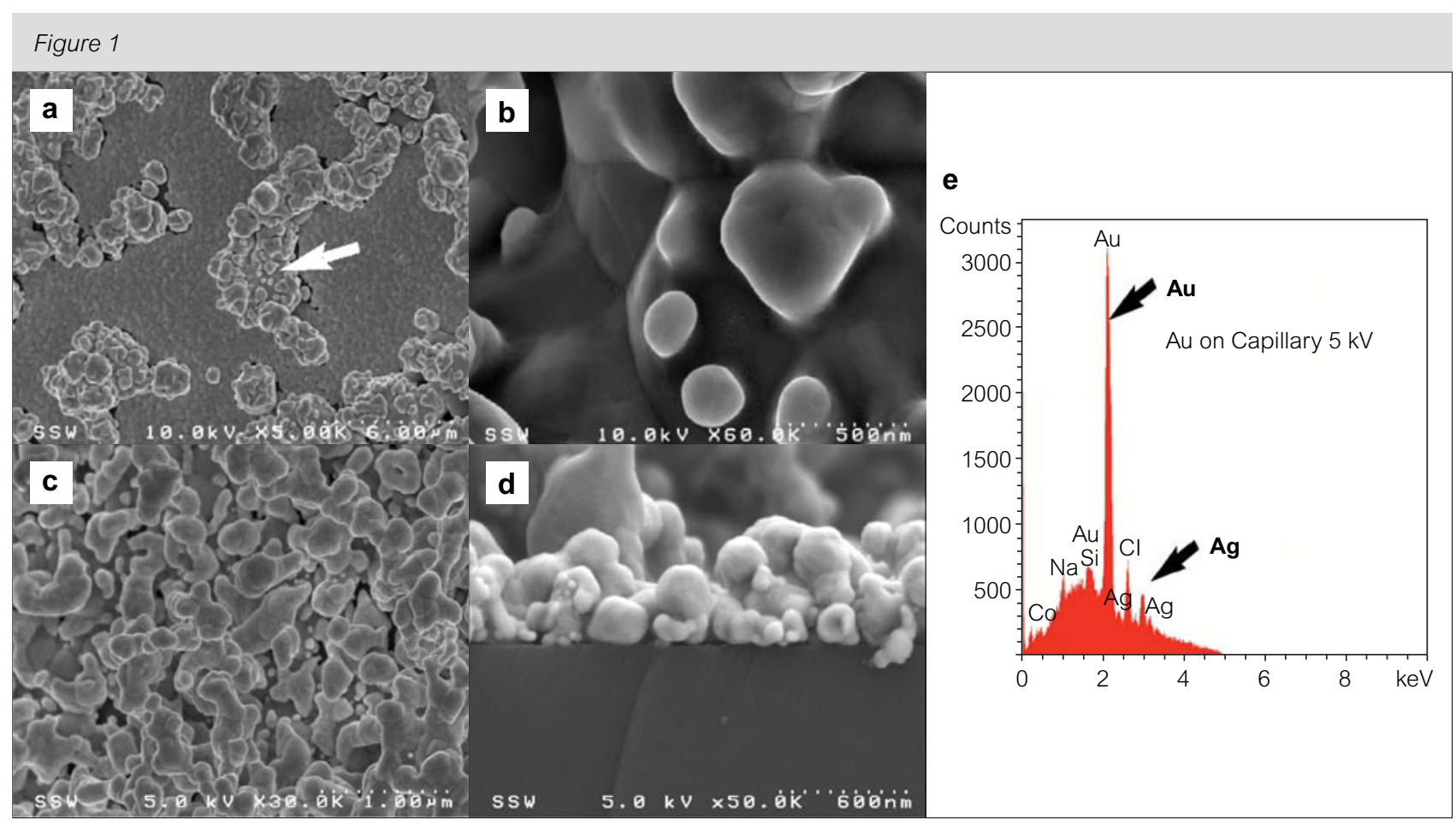

SEM images of the Au films prepared inside a glass capillary. a) Image of a gold-on-gold film taken at 5,000X magnification. b) Same site as the image in panel a (see arrow) taken at 60,000X magnification. The arrow points to a typical Au nanoparticle cluster against the backdrop of much smaller, densely-packed Au particles that coat the glass. c) Image of Au layered on a base film of Ag (30,000X magnification). d) Side view of panel c showing the Au film attached to the glass capillary wall (bottom of image), between which is sandwiched a barely-visible thin Ag coating (50,000X magnification). e) Energy-dispersive X-ray (EDX) spectrum of the gold-on-silver film from panel c 
(from the diethylene glycol/ $\mathrm{AuCl}_{3}$ solution) was laid down on the capillary wall upon which gold islands were deposited from the aqueous sodium citrate solution. The resultant film morphology is shown in Figure 1 (panels a and b). A related approach was developed for the deposition of gold nanoclusters on a silver monolayer, which attaches very firmly to glass. Now the porous gold layer covered the entire surface (as compared to just forming islands of gold), which greatly increased surface area while at the same time anchoring more firmly to the side of the capillary (see figure 1, panels $c, d$ and $e$ ).

\section{Microwave-assisted, continuous flow organic synthesis}

We have designed a new continuous flow reactor platform comprised of capillary-sized tubes that traverse the cavity of a focused Biotage Initiator Microwave Synthesizer (Figure 2) $(16,17)$. The reactants can be premixed and flowed into the reactor through one syringe, or more efficiently, kept separate and flowed into a mixing chamber where they combine and move into the capillary (see the 3-component coupling example demonstrating this concept in Figure 2) (18). Depending on the flow rate, the moving solutions spend between two and four minutes in the microwave chamber (i.e., residence time), thus they must be provided with what is necessary in order to complete the reaction during this very brief period of time. This is where we have applied our metal-film technology to provide a surface to promote reactions either by the intensively hot film surface, which could involve a homogeneous catalyst in the flow stream, or through the catalytic activity of the film itself. With this flow technology and the various gold-lined capillaries in hand, we investigated their application in a number of mechanistically-diverse gold-catalysed organic transformations.

\section{Hydrosilylation of terminal alkynes}

The first MACOS transformation that the Au-lined capillaries (i.e., gold-on-gold) were used for was the hydrosilylation of alkynes (19). A formal addition reaction, the process involves a number of discrete steps making the catalytic process moderately complex (vide infra). After evaluating a number of solvents, flow rates, and power settings, the optimized conditions in Table 1 were applied to a wide array of substrate pairings. The method proved to be both general and high yielding. Reactive functional groups such as cyano, alcohols, chlorides, aromatics/ heteroaromatics, and ethers were well tolerated.

Figure 2

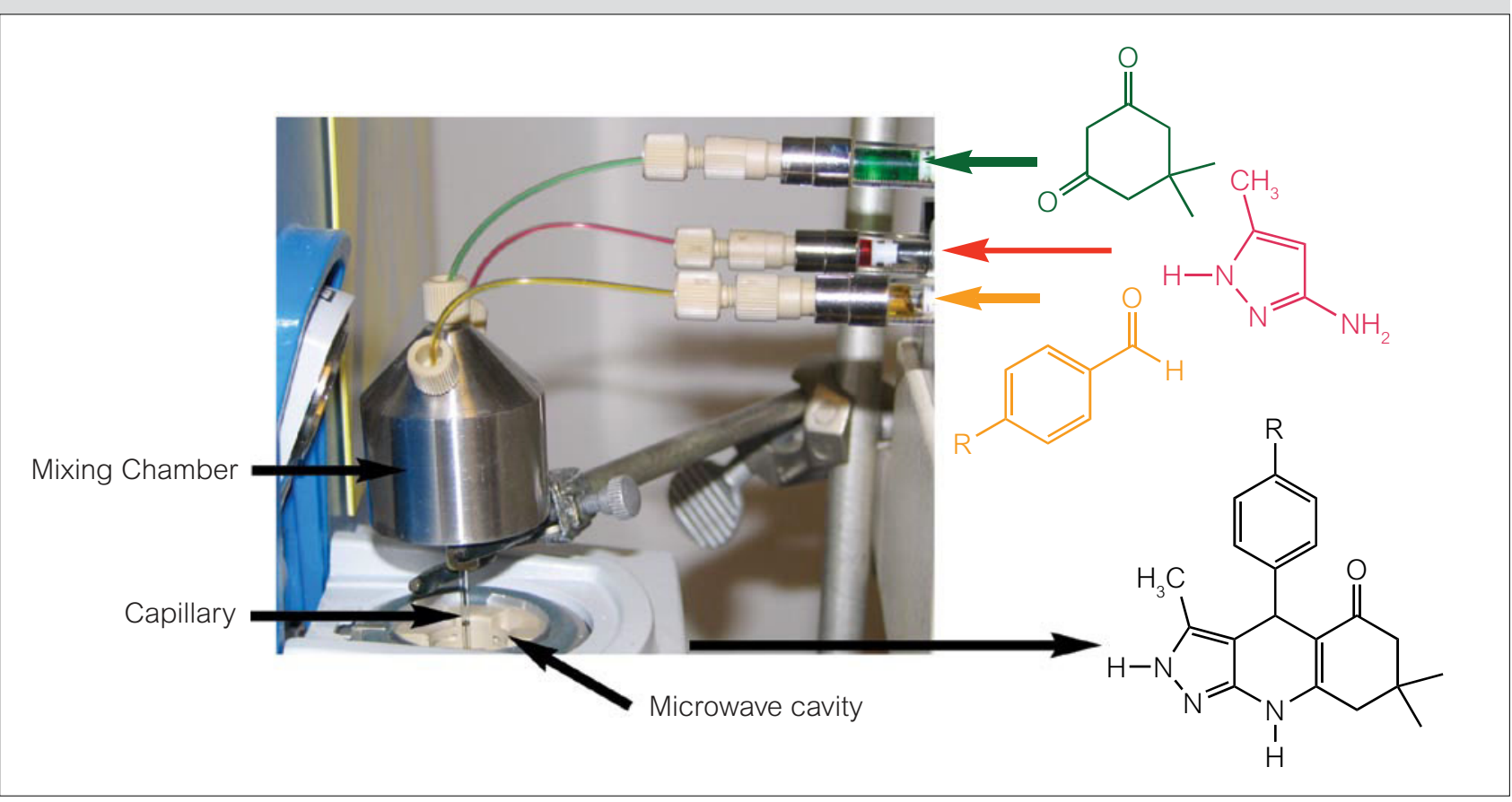

Photograph of a 3-inlet MACOS reactor depicting a 3-component coupling reaction to prepare cyclic products 
Table 1. Hydrosilylation of terminal alkynes catalysed by gold-coated capillaries using Microwave-Assisted, Continuous Flow Organic Synthesis (MACOS)

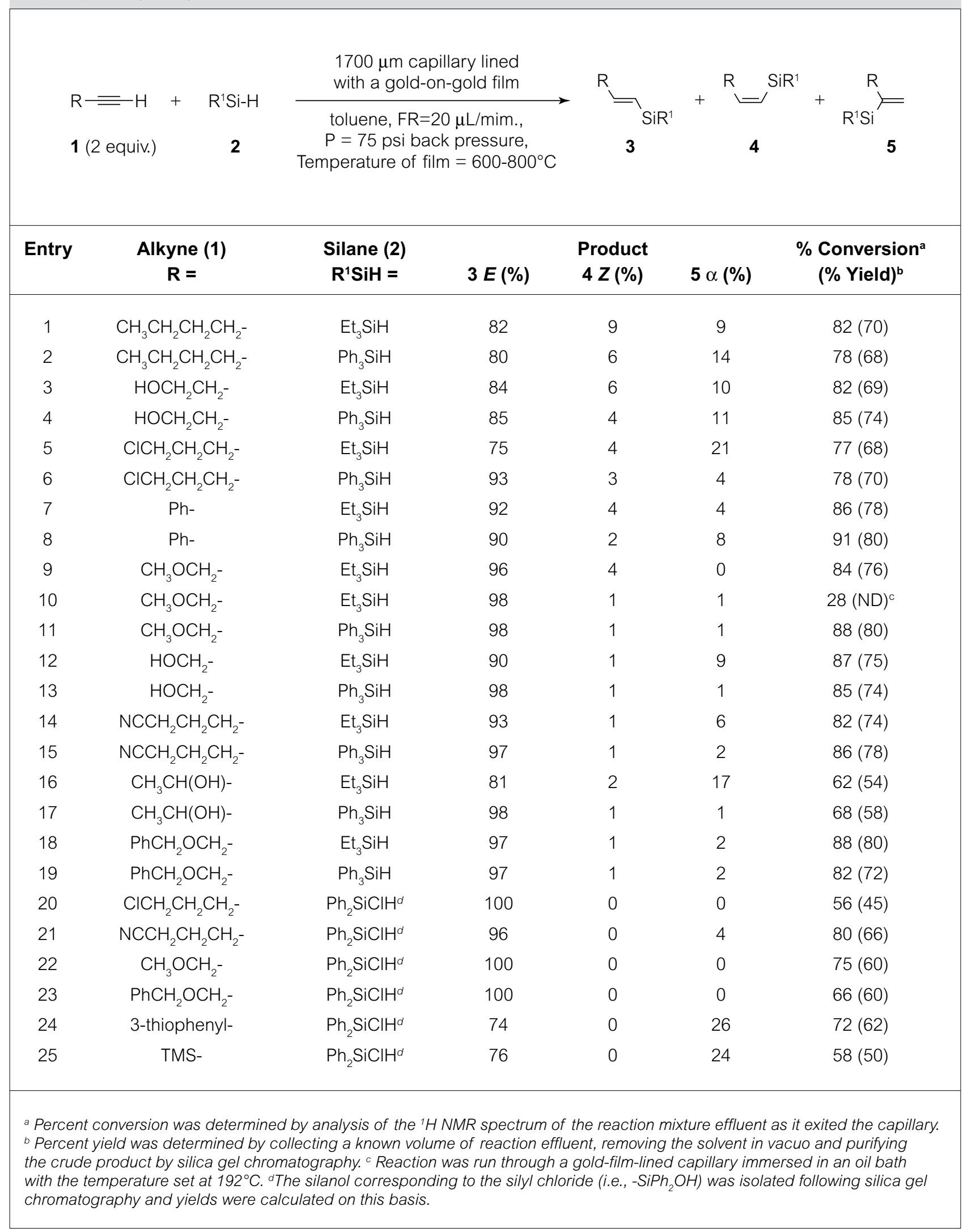


Table 2. A three-component MCR procedure for the preparation of propargyl amines by MACOS using a Au-coated capillary flow tube

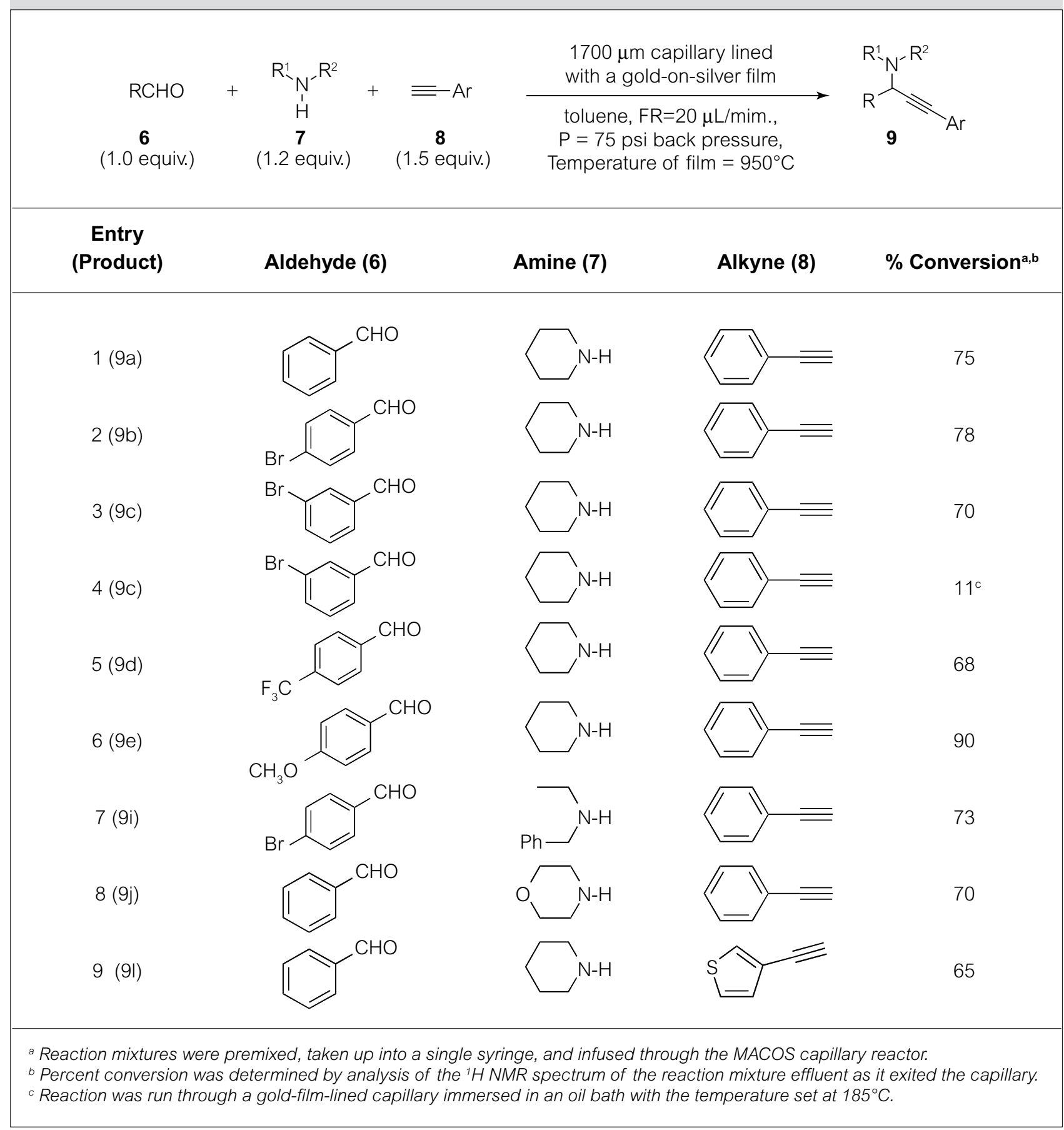

Triethyl-, triphenyl-, and chlorodiphenyl silane were all suitable hydrosilylating agents. Hydrometallation was regioselective for placement of the silicon moiety on the terminal carbon of the alkyne. When an alkyl alkyne was used stereospecificity was lowest (entries 1-6), but $E$ selectivity for the terminal silane product was always greater than 90 percent.

\section{Multi-Component Coupling Reaction (MCR) for the preparation of propargylamines}

The first MCR reaction we evaluated in MACOS using gold-lined flow tubes was the condensation/ addition of aldehydes, amines, and alkynes (20). 
<smiles></smiles>

10

(1.0 equiv.)<smiles>[R]C#C</smiles>

11

(3.0 equiv.)

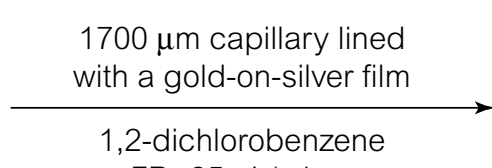

$\mathrm{FR}=25 \mu \mathrm{L} / \mathrm{mim}$.

$P=75$ psi back pressure,

Temperature of film $=950^{\circ} \mathrm{C}$<smiles>[R]C(=O)c1c([R])ccc2ccc[X]c12</smiles>

12<smiles>[R]C(=O)c1cc([R])cc2cccc[X]12</smiles>

13

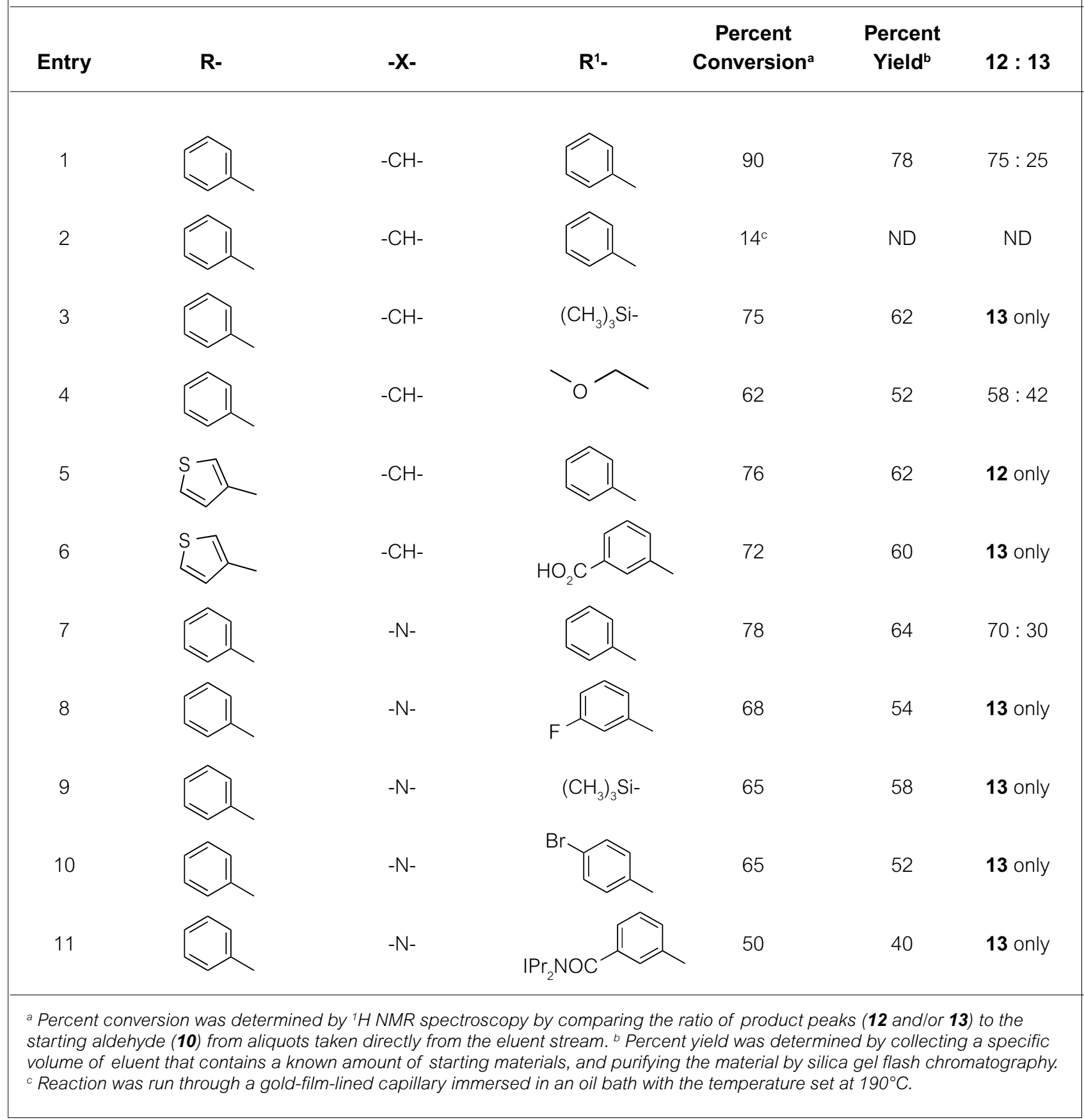


a)

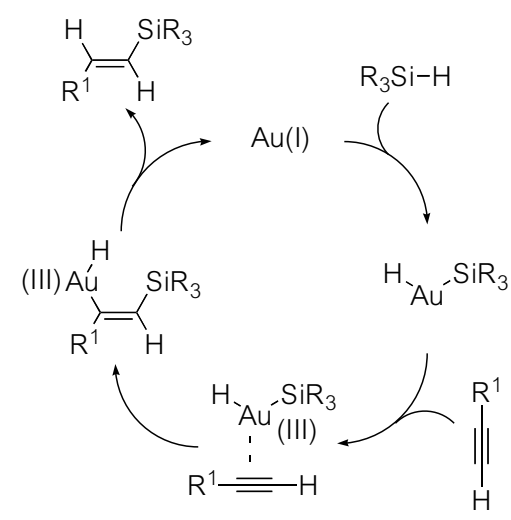

b)

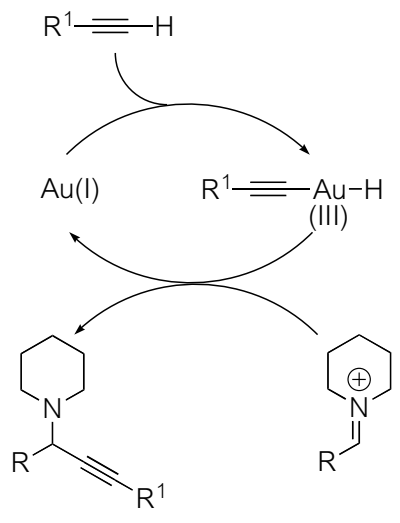

c)<smiles>[R]C#Cc1ccccc1C=O</smiles>

Mechanism of homogeneous Au-catalyzed transformations. a) Au(I)-catalysed hydrostannylation of terminal alkynes. b) Au(I)-catalysed terminal alkyne additions to imines. C) Au(III)-catalysed benzannulation of aromatic carbonyls and alkynes

Percent conversion ranged from 65 to 90 percent across a variety of electron rich/poor aldehydes and the process seems quite general for secondary alkyl amines (Table 2). Presumably, condensation takes place in the syringe prior to delivery of the reacting solution into the flow tube.

\section{Benzannulation of 2-alkynylbenzaldehydes}

In a mechanistically interesting and complex application, alkynes were flowed into the reaction tube together with a limiting amount of alkynylsubstituted benzaldehyde derivatives through the gold-on-gold-lined capillaries (Table 3) (21). Again, very good conversions (and corresponding yields) were obtained for a wide variety of products.

\section{Mechanistic considerations}

It is striking that the variety of transformations can be catalysed by these gold-coated capillaries while they are irradiated with microwaves. On the surface, all three processes point to very different catalytic cycles, even in instances where similar reacting functional groups are present (e.g., aldehydes, alkynes). All of these processes are known to be catalyzed with homogeneous $\mathrm{Au}(\mathrm{I})$ and/or $\mathrm{Au}(\mathrm{III})$ complexes and sample catalytic cycles for each are shown in Figure 3. Gold-catalysed hydrosilylation (Fig. 3, panel a) has been shown to be catalysed by Au(III) complexes and supported Au nanoparticles; interestingly, given the results above, metallic gold has been reported to be catalytically inactive in this process $(22,23)$. Li and coworkers have provided a mechanism for the Au-mediated addition of alkynes to imines that involves the formation of a terminal alkynyl-gold species (24). The proposed mechanism seems reasonable, yet it is interesting that the hydrosilylation, which takes place under very similar reaction conditions, does not seem to experience any $\mathrm{C}-\mathrm{H}$ activation of the alkyne (Fig. 3, panel b). The benzannulation process similarly proposes adjustment of oxidation state of the gold between I and III during the formation of the aromatic ring (Fig. 3 , panel c) $(9,25)$. Interestingly, both hydrosilylation and benzannulation have been demonstrated to be promoted by $\mathrm{Au}(\mathrm{I})$ and $\mathrm{Au}(\mathrm{III})$ complexes, but also by supported gold nanoparticles. This means one of two things for these Au-mediated processes: either the various oxidation states of gold interconvert under the reaction conditions that these reactions are performed and one single pathway is involved, or each gold species operates with its own distinctive mechanism. Attempts to draw conclusions about these mechanisms in MACOS are hampered by the 
lack of certainty about the composition of the film. There is undoubtedly both $\mathrm{Au}(0)$ and $\mathrm{Au}$ oxide(s) present on the surface, or just below the surface layer of the gold film.

\section{Reproducibility of reaction and film robustness}

One concern for this metal-film/MACOS technology is reproducibility. Unlike a conventional batch reaction that can be performed several times using the same source of reactant, catalyst etc., there is the potential for greater variability between MACOS runs performed in different capillaries. There are a number of aspects associated with the production of the film itself (e.g., quality of glass surface, exact concentration of film-forming solutions, exact temperature of ovens, the precise time films are left to develop, etc.) and the actual MACOS procedure that would impact on reproducibility. Admittedly, the hardest thing that we have found to control, let alone precisely reproduce from run-to-run is the exact temperature of the film (vide infra). To address the statistical reproducibility of our technology, we randomly chose the reaction detailed in entry 10 , Table 1 and ran the reaction five times using five separately prepared gold-on-gold capillaries. The measured percent conversions were $78,81,82,85$ and 88 , which corresponds to an average conversion of $82.8 \%$ with a standard deviation $(\sigma)$ of 3.4 . Based on these findings, we believe that MACOS runs with metal films are reasonably reproducible.

Another metric often looked at for reactions that use supported catalysts is run-to-run reuseability. In our case, we were concerned about the robustness of the gold film and its possible poisoning by the substrates in the flowing reactions stream. To evaluate this, the reaction in entry 10 (Table 1) was repeated five separate times using the same capillary. The percent conversion obtained in succession was $52,91,75,80$, and 72 . While the first run was a little low leading to a larger than ideal deviation $(\sigma=12.8)$, good levels of conversion were attained in the other runs.

\section{Conclusions}

Gold thin films have proven to be highly active promoters of three mechanistically-diverse transformations: hydrosilylation, alkyne additions to imines, and benzannulations. The reactions are driven by microwave irradiation that heats the gold film between 600 and $950^{\circ} \mathrm{C}$. There is good run-to- run reproducibility and the gold-lined flow tubes can be reused.

\section{Acknowledgement}

This work was funded by the Natural Sciences and Engineering Research Council (NSERC) of Canada, the Ontario Research and Development Challenge Fund (ORDCF), and the Ontario Centres of Excellence (OCE). The authors graciously acknowledge the donation (in part) from Varian Inc. of a GCMS to evaluate the products of the above transformations.

\section{About the authors}

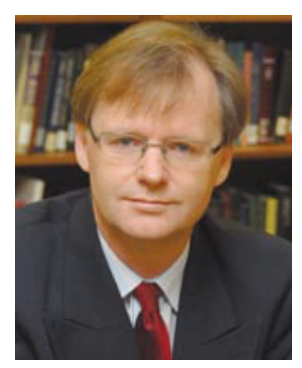

Michael Organ is a Professor of Chemistry at York University in Toronto. He has published over 80 manuscripts, provided more than 200 invited lectures, and spun out two start-up companies.

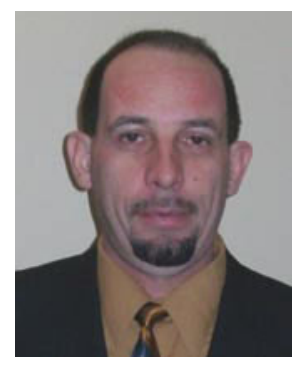

Gjergji Shore has just completed his $\mathrm{PhD}$ degree in synthetic organic chemistry.

\section{References}

1 A.S.K. Hashmi, Gold Bull., 2007, 37, 51-65

2 W. Schwemberger and W. Gordon, Chem. Zentralbl., 1935, 106, 514-514

3 F. Gasparrini, M. Giovannoli, D. Misiti, G. Natile and G. Palmieri, J. Org. Chem., 1990, 55, 1323-1328

4 F. Shi, Y. Deng, H. Yang and T. SiMa, J. Chem. Soc., Chem. Commun., 2001, 345-346

5 Xu, Y. Imamura, M. Fujiwara and Y. Souma, J. Org. Chem., 1997, 62, 1594-1598

6 Y. Ito, M. Sawamura and T. Hayashi, J. Am. Chem. Soc., 1986, 108, 6405-6406

7 B.F. Straub, Chem. Commun. 2004, 1726-1728

8 A.S.K. Hashmi, T.M. Frost, J.W. Bats, J. Am. Chem. Soc. 2000, 122, 11553-11554 
9 A.S.K. Hashmi, T.M. Frost, J.W. Bats, Org. Lett. 2001, 3, 3769-3771

10 Asao, K. Takahashi, S. Lee, T. Kasahara, Y. Yamamoto, J. Am. Chem. Soc. 2002, 124, 12650-12651

11 L.-U. Meyer and A. de Meijere, Tetrahedron Lett., 1976, 497-500

12 G. Shore, M.G. Organ, Chem. Commun. 2008, 838-840

13 G. Shore, S. Morin, D. Mallik, M.G. Organ, Chem. Eur. J. 2008, 14, 1351-1356

14 G. Shore, S. Morin, M.G. Organ, Angew. Chem. Int. Ed. 2006, 45, 2761-2766

15 P. He, S.J. Haswell, P.D.I. Fletcher, Lab Chip, 2004, 4, 38-41

16 E. Comer, M.G. Organ, J. Am. Chem. Soc. 2005, 127, 8160-8167

17 M.G. Organ, E. Comer, Chem. Eur. J. 2005, 11, 7223-7227
18 S. Bremner, M.G. Organ, J. Comb. Chem. 2007, 9, 14-16

19 G. Shore, M.G. Organ, Chem. Eur. J. 2008, 14, 9641-9646

20 G. Shore, W.J. Yoo, C.J. Li, M.G. Organ, Chem. Eur. J. 2010, 16, 126-133

21 M.G. Organ, G. Shore, M. Tsimerman, Beilstein J. Org. Chem. 2009, 5, No. 35

22 A. Corma, C. GonzOlez-Arellano, M. Iglesias, F. Sonchez, Angew. Chem. Int. Ed. 2007, 46, 7820-7822

23 A.M. Caporusso, L.A. Aronica, E. Schiavi, G. Martra, G. Vitulli, P. Salvadori, J. Organomet. Chem. 2005, 690, 1063-1066

24 C. Wei, C.J. Li, J. Am. Chem. Soc. 2003, 125, 9584-9585

25 A.S.K. Hashmi, T.M. Frost, J.W. Bats, Org. Lett. 2001, 3, 3769-3771 